\title{
Strategies of management of deep spinal infection: from irrigation and debridement to vacuum-assisted closure treatment
}

\author{
Ismail Daldal ${ }^{1}$, Alpaslan Senkoylu ${ }^{2}$ \\ ${ }^{1}$ Department of Orthopaedics and Traumatology, Lokman Hekim Akay Hospital, Ankara, Turkey; ${ }^{2}$ Department of Orthopaedics and Traumatology, \\ Gazi University, Ankara, Turkey \\ Contributions: (I) Conception and design: All authors; (II) Administrative support: A Senkoylu; (III) Provision of study materials or patients: All \\ authors; (IV) Collection and assembly of data: All authors; (V) Data analysis and interpretation: All authors; (VI) Manuscript writing: All authors; (VII) \\ Final approval of manuscript: All authors. \\ Correspondence to: Alpaslan Senkoylu. Department of Orthopaedics and Traumatology, Gazi University, Besevler, Ankara 06510, Turkey. \\ Email: drsenkoylu@gmail.com.
}

\begin{abstract}
Postoperative surgical site problems (PSSPs) following spinal surgery may lead to patient mortality, increased treatment costs and possible recurrent medical interventions. Despite efforts to reduce spinal surgery-related infection rates, complications are common and significantly increased by patient comorbidities. Since PSSPs occur regardless of deterrent measures, it is essential to distinguish the related risk factors. Different treatment conventions for PSSPs, for example, antibiotic treatment, debridement, soft tissue care and removal of implants have been prescribed with blended outcomes. The utilization of the wound vacuum-assisted closure (VAC) system has gained increasing popularity in the management of deep wound infections after deformity surgery.
\end{abstract}

Keywords: Scoliosis; wound infection; spinal instrumentation; surgical site infections

Submitted Oct 19, 2019. Accepted for publication Nov 08, 2019.

doi: $10.21037 /$ atm.2019.11.60

View this article at: http://dx.doi.org/10.21037/atm.2019.11.60

\section{Introduction}

Postoperative surgical site problems (PSSPs) following spinal surgery may lead to patient mortality, increased treatment costs and possible recurrent medical interventions (1). Despite efforts to reduce spinal surgeryrelated infection rates, complications are common and significantly increased by patient comorbidities.

It is known that both minor and major complications related to infection have increased in recent years and as a result, the treatment costs have risen. Scoliosis Research Society Mortality and Morbidity (SRS M\&M) database showed mean spinal infection rates of $3.2 \%$ from 2012 to 2015 (2). According to these results, interestingly, previous infection rates reports from SRS were higher. In other words, the overall complication rate decreased by approximately $10 \%$ within 12 -year period of time. Despite the fact that preclude from infection and therapeutic options have improved as of late, postoperative surgical site infections still substantially affect clinical outcome, and there stays a need to recognize risk factors and related conventions to limit its event.

Many large databases have been used to identify patient specific risk factors to generate risk-adapted ratios of hospital acquired conditions, such as postoperative infection. Unfortunately, these large databases do not contain detailed information about disease-specific patient characteristics $(3,4)$. Nevertheless, a recent review of SRS M\&M Committee gave some important information about PSSP. Sillingford et al. concluded that, incidence of PSSPs was 12.1 per 1,000 patients and these problems were significantly higher in patients with kyphosis (5). Since PSSPs occur regardless of deterrent measures, it is essential to distinguish the related risk factors and all these are summarized in Table 1. 
Table 1 Risk factors for postoperative infection after instrumented spinal surgery in pediatric and adult population (5-10)

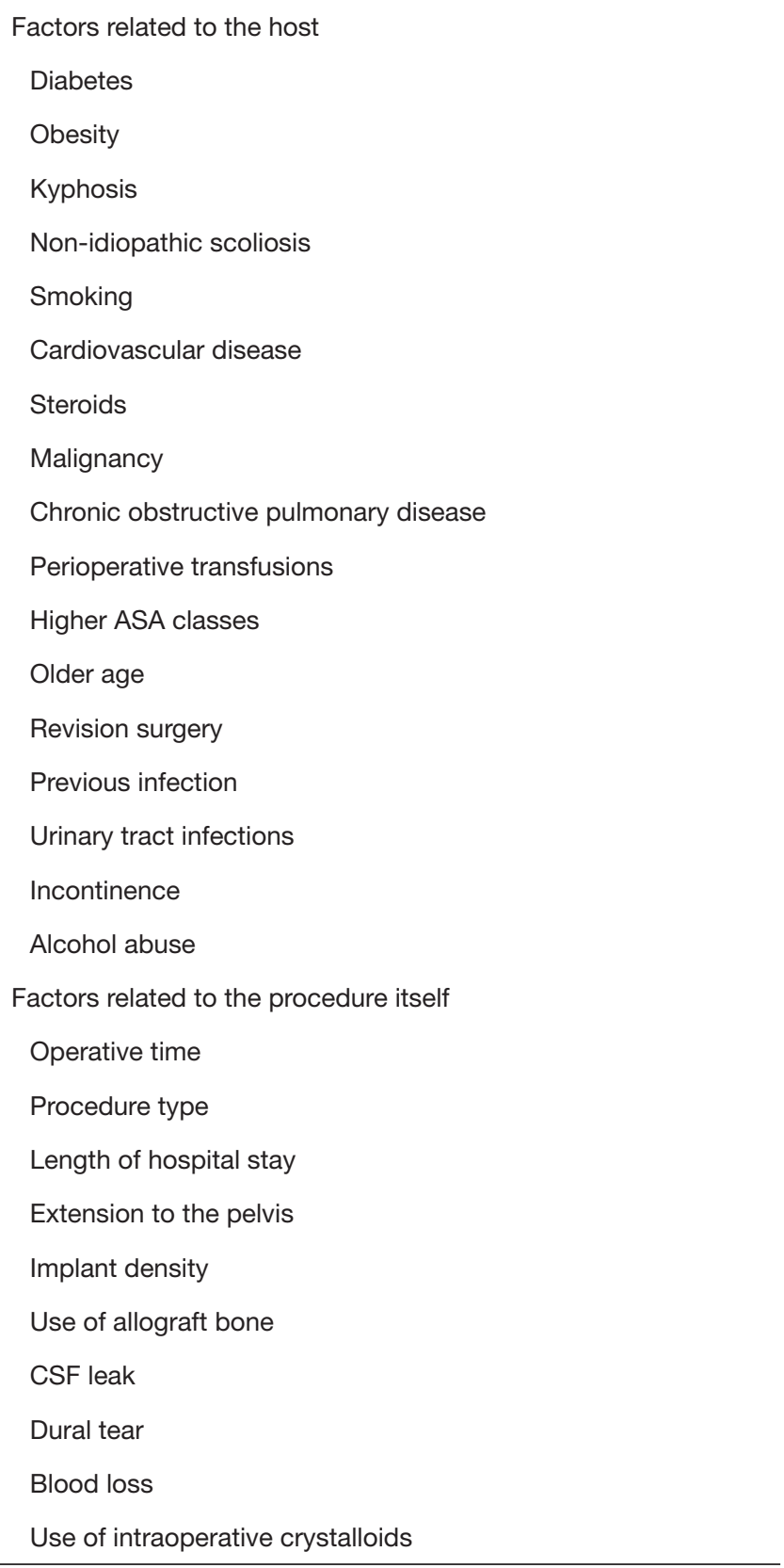

ASA, American Society of Anesthesiologists; CSF, cerebrospinal fluid.

\section{Incidence and causative microorganisms}

PSSPs rates in patients experiencing long segment instrumented thoracolumbar fusion surgery in general are $0.7 \%$ to $4.4 \%$ in different studies. Of note, most studies did not differentiate between superficial surgical site problems, deep surgical site infections, wound dehiscence or death space infections (5-13).

Distinguishing of most basic causative microorganisms is significant for prophylaxis management as well as exact treatment protocols if PSSPs exist. According to The Johns Hopkins University study, culture growth was negative 18 out of 65 deep wound infection cases (10). That means causative agent can not be identified within almost one third of the deep wound infection cases. Although, both gram-positive and gram-negative microorganism could be isolated from PSSPs, the most common causative bacteria are Staphylococcus, especially, coagulase-negative and Stapbylococcus aureus subtypes (10). On the other hand, low virulent agents such as Propionibacterium acnes and Staphylococcus epidermidis in normal skin flora should be isolated from the most of the late surgical site infections (13).

Gram-negative organisms including Eschericia coli, Enterobacter and Pseudomonas are more common in nonidiopathic scoliosis patients such as genetic/syndromic and neuromuscular cases. Furthermore, there are more than one gram-negative bacteria isolated in significant number of cases. This propensity may be due to contamination from bowel/bladder incontinence, gastrostomies or tracheostomies $(10,13)$.

\section{Antibiotics}

In recent years, combined antibiotherapy strategy by utilizing intravenous vancomycin, standard prophylactic antibiotics and local vancomycin powder has been executed for spinal instrumentation procedures because of an expansion in methicillin-resistant Staphylococcus aureus (MRSA) cases in numerous spine clinics (14). There is lack of adequate proof to make a recommendation possibly in support of the prophylactic utilization of vancomycin contrasted with other antimicrobial agents with lessen contaminations with MRSA.

The greatest possible problem at this point is the concern that routine use of broad-spectrum antibiotics in the perioperative period may produce antibiotic resistant bacteria species that might be hard to treat and annihilate $(15,16)$. In other respect, presence of risk factors broad spectrum of antibiotics which cover gram-negative and gram-positive microorganisms could be given.

In common uncomplicated spinal surgical approaches, the superiority of one agent, portion, or course of organization over some other has not been clearly illustrated, yet. When deciding the fitting medication 
decision, the patient's risk factors, length and complexity of the surgical approach, and issues of antibiotic resistance and/or possible drug allergy and cross reactions must be considered (15). Multidisciplinary team work is also crucial for the management of complex wound problems. Wound swaps or pus specimens should be sent to infectious diseases and clinical microbiology department for cultural studies. Evaluation of general metabolic and nutritional status is important for wound healing and treatment of infection.

\section{Vancomycin powder}

Local usage of vancomycin powder is modest, has expansive coverage against run of the mill agents responsible for deep spinal wounds, and appears to convey a lower risk of systemic complications than intravenous form. Most studies have bolstered its utilization, detailing diminished rates of postoperative surgical site infections and no adverse reactions (17-19).

O'Neil et al. (20) revealed a $13 \%$ decrease in the rate of postoperative deep PSSPs in patients experiencing posterior spinal instrumented surgery of wound problems. Also, Sweet et al. (21) revealed a $2.4 \%$ lessening in the occurrence of postoperative SSIs in patients experiencing spinal procedures utilizing vancomycin powder prophylaxis.

For the scoliosis surgery, vancomycin powder mix with allograft and this mixture is spread on fusion bed. Most investigations utilized $1 \mathrm{~g}$ of vancomycin powder and a few examinations utilized 1.75 or $2 \mathrm{~g}$, which may not be adequate to counteract contamination for these bigger approaches, and further examinations are expected to assess this point $(20,22,23)$. Authors keep on utilizing $2 \mathrm{~g}$ for long segment spinal surgeries, yet in addition question whether a bigger portion might be gainful.

There are some concerns about the complications of vancomycin powder application. According to a systematic review by Ghobrial et al. (24), sixteen published data were illustrated with a total of 9,721 patients and the overall adverse event rate with vancomycin powder was $0.3 \%$. The most common complication was negative seroma in 19 patients. They also reported an increased in cultured gram-negative or polymicrobial spine infections when using vancomycin powder for prophylaxis. Another concern is some in-vitro studies have shown that high doses of local antibiotics have a cytotoxic effect on osteoblasts, leading to lack of spinal fusion. Rathbone et al. (25) reported vancomycin has less toxic on osteoblasts than other commonly used antibiotics. Moreover, any lack of fusion rate or increased pseudoarthrosis rate has not been reported in other clinical studies $(21,22)$.

\section{VAC dressing treatment}

The VAC dressing system incorporates dark polyurethane delicate froth which is sliced to fit the hole of the wound and afterward set to fill the whole twisted zone or dead space in different layers if fundamental.

The controlled utilization of subatmospheric pressure dressing (SPD) in the VAC has been gaining popularity subacute and chronic PSSPs. VAC uses negative pressure to close the dead space, assists debridement of necrotic tissue, and helps the formation of granulation tissue by stimulating wound vascularity. Different studies have demonstrated to be the primary cause of more prominent fibroblast migration, bringing about better tissue, expanded granulation tissue growing, and angiogenesis. Thus, this strategy for the complex soft tissue problems has demonstrated a quickened twisted recuperating when contrasted with that of traditional techniques $(26,27)$ (Figure 1,2).

As an important technique tip, VAC system should be applied after debridement of infected and necrotic tissue. This helps to increase effectivity of system. Authors use silver coated sponges unless the presence of silver allergy. These sponges should be changed in every 4-5 days and wound debridement can be repeated at this time if necessary. Decreasing the amount of suction below to $20 \mathrm{mlt} /$ day means a good control of infection. After obtaining sufficient granulation tissue with decreasing amount of drain wound can be closed either primary or secondary with flap surgery (Figure 2).

Specific contraindications of VAC system in postop deep spine infection should be presence of dural tear or cerebrospinal fluid leakage and silver sensitivity or allergy. Exposure of dura due to extensive laminectomy is not a contraindication for VAC system since intact dura is a strong anatomic barrier.

Canavese et al. reported the results of surgical debridement and VAC treatment in 14 pediatric patients with complex deformity who developed early sub fascial infection and posterior spinal instrumentation and fusion. In their study, complete recovery was achieved in all patients and no implant removal was necessary (28). Lee et al. reported that VAC therapy was safe even in patients with dural injury after posterior spinal fixation (29). Watt and Dunn conducted a retrospective study on a case series 

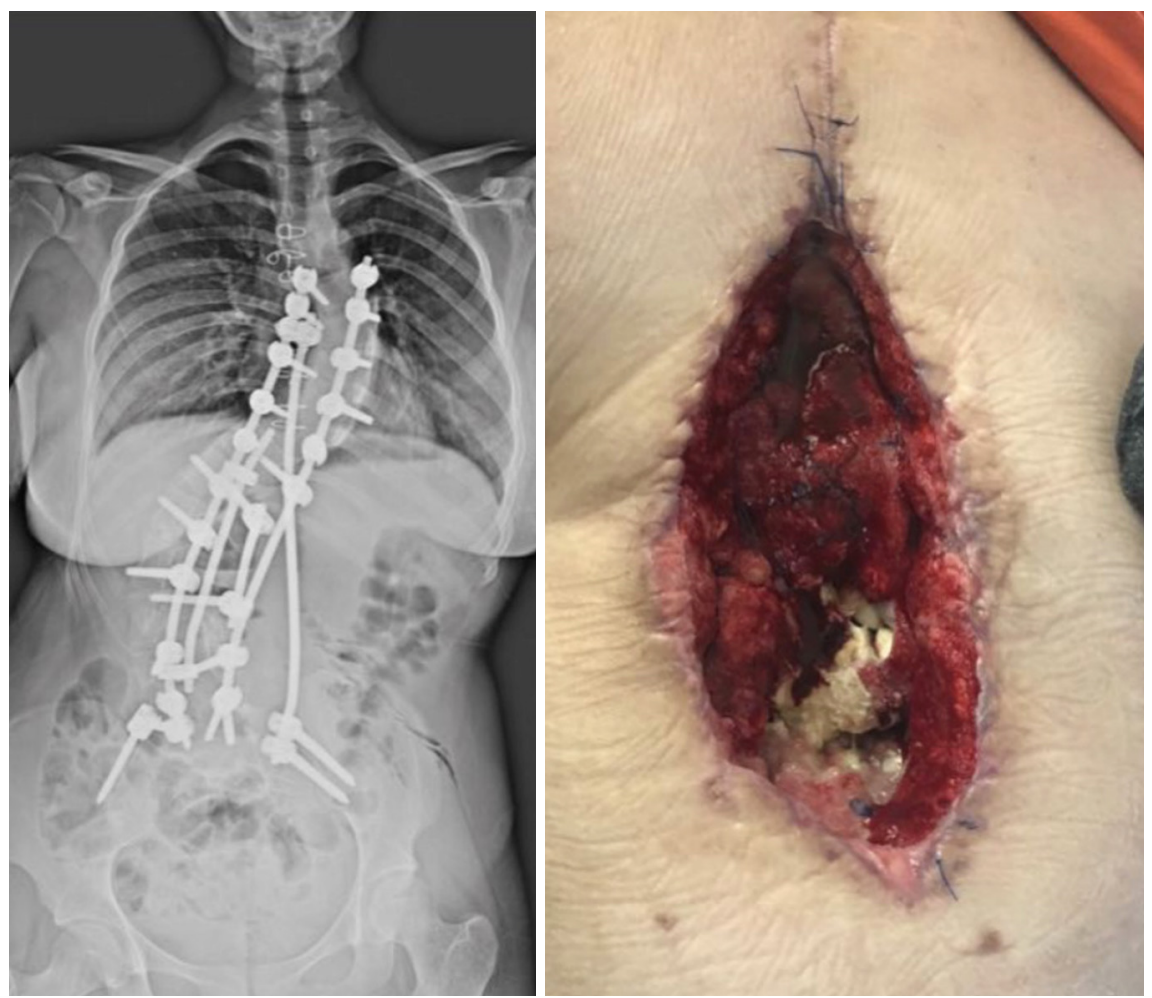

Figure 1 A myelomeningocele patient who complicated with deep wound infection after a complex scoliosis surgery.
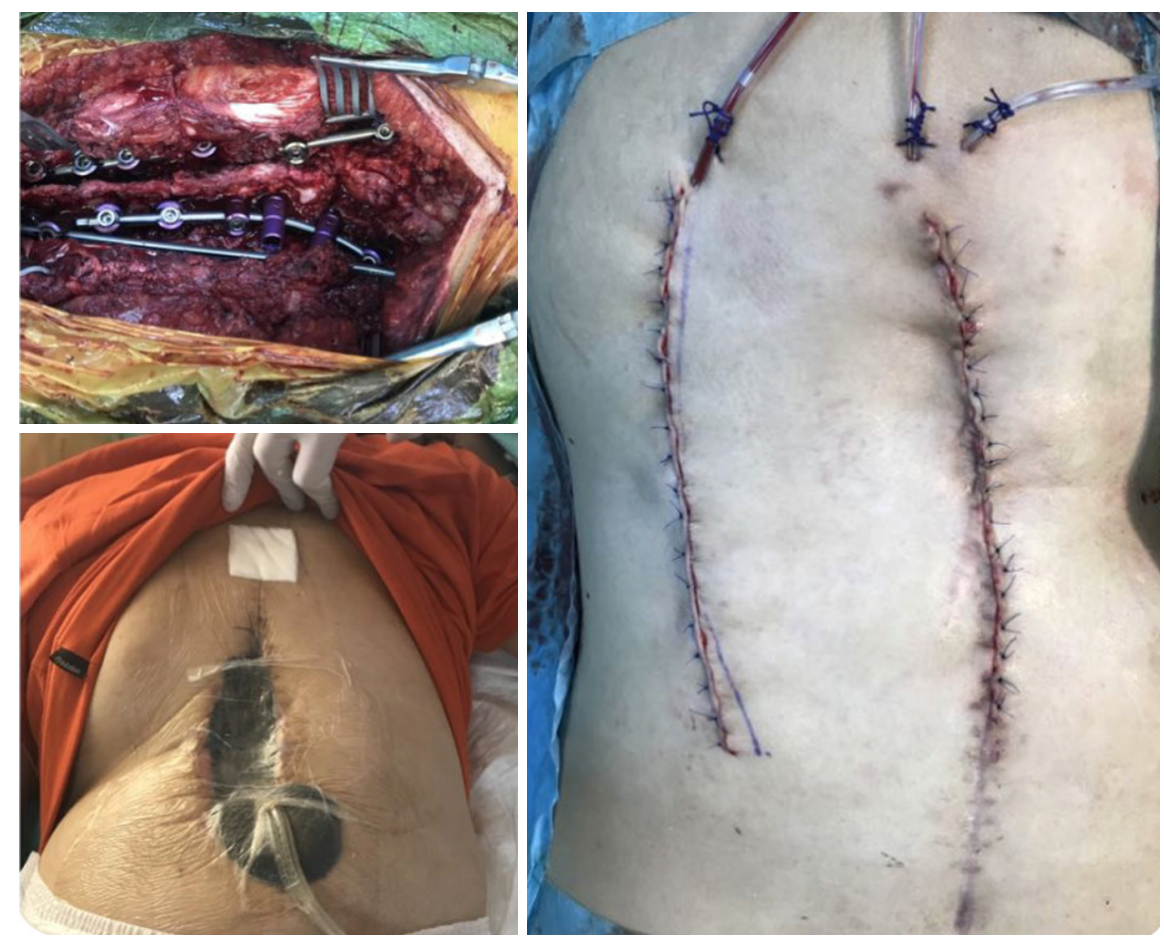

Figure 2 The application of VAC system after serial debridements and finally, wound closure with flap surgery have been done. VAC, vacuum-assisted closure. 


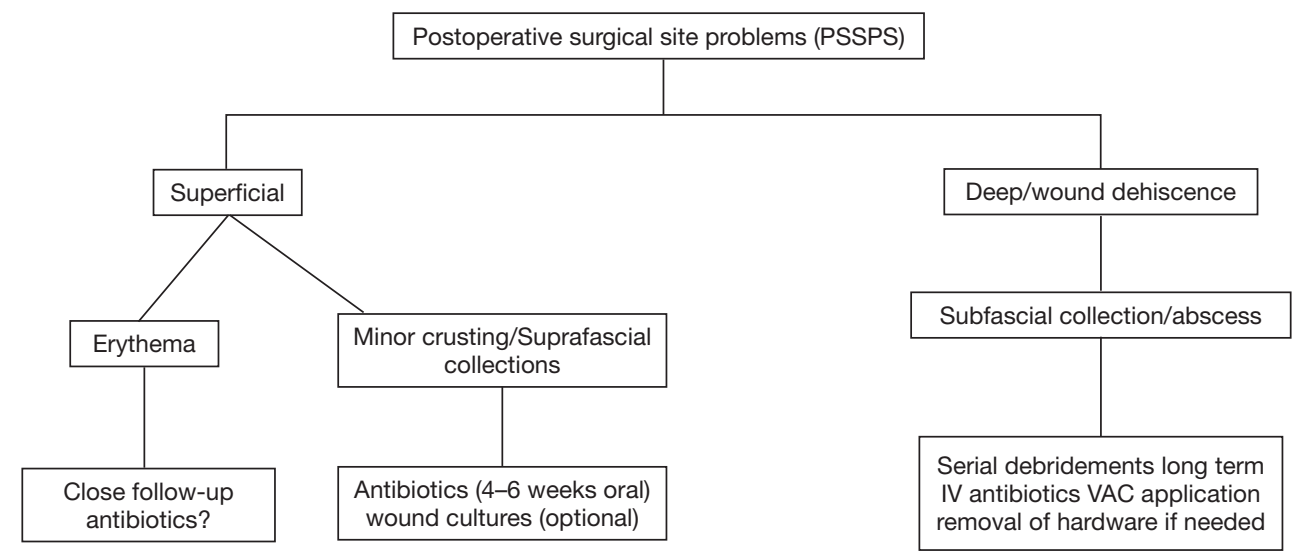

Figure 3 This flowchart summarizes management of postoperative surgical site problems in deformity surgery. Treatment of superficial in other word suprafacial infection is relatively easy. However, deep wound infection needs more complex and multidisciplinary approach.

including heterogeneous group of 3,448 patients with different etiologies. They found 19 early postoperative (within 3 months) deep wound infection and all these treated with debridement, vacuum dressings and longterm antibiotic treatment. Implant removal was needed in only one patient. They concluded that this management is effective for deep wound infections after spine surgery and allows graft and instrument retention (30).

\section{Implant removal}

Removal of implants could be needed for persistent deep wound infection. In the 1990s, Richards reported that the implant removal rates in patients with sub facial spinal infection was up to $35 \%$ (31). However, recent improvements in wound care allow implant retention especially for acute deep wound infection (30). Hedequist et al. reported 26 delayed deep wound infection cases within 1,771 deformity cases. Eventually, implants were removed in these 26 patients (32). Patients who need implant removal after deformity surgery should be informed well regarding curve deterioration following removal of instruments. Farshad et al. conducted a study on seven idiopathic scoliosis patients need implant removal because of late infection. They demonstrated loss of Cobb's angle correction of about one third at the end of 10-year follow-up (33).

\section{Conclusions}

Scoliosis surgery can be complicated by surgical site problems. More often than not, these infections bring about expanded mortality, morbidity and medicinal services costs, and of course prolonged hospital stay. It is essential to identify the variables that could increase the related risk of PSSPs in order to prevent this devastating complication. Management of PSSPs was summarized with a flowchart in Figure 3. Outcome could be satisfactory in most of cases with serial debridements, VAC system and IV antibiotics in the presence of postoperative deep wound infection.

\section{Acknowledgments}

Authors would thank to Dr. Akif Albayrak for sharing pictures of his case.

\section{Footnote}

Conflicts of Interest: The authors have no conflicts of interest to declare.

Ethical Statement: The authors are accountable for all aspects of the work in ensuring that questions related to the accuracy or integrity of any part of the work are appropriately investigated and resolved.

\section{References}

1. Collins I, Wilson-MacDonald J, Chami G, et al. The diagnosis and management of infection following instrumented spinal fusion. Eur Spine J 2008;17:445-50.

2. Cognetti D, Keeny HM, Samdani AF, et al.

Neuromuscular scoliosis complication rates from 2004 
to 2015: a report from the Scoliosis Research Society Morbidity and Mortality database. Neurosurg Focus 2017;43:E10.

3. User Guide for the 2014 ACS NSQIP Participant Use Data File. American College of Surgeons 2015. Available online: https://www.facs.org/ /media/files/quality\%20 programs/nsqip/nsqip_puf_userguide_2014.ashx

4. Martin CT, Pugely AJ, Gao Y, et al. Incidence and risk factors for early wound complications after spinal arthrodesis in children: analysis of 30-day followup data from the ACS-NSQIP. Spine (Phila Pa 1976) 2014;39:1463-70.

5. Shillingford JN, Laratta JL, Reddy H, et al. Postoperative surgical site infection after spine surgery: An update from the Scoliosis Research Society (SRS) Morbidity and Mortality Database. Spine Deformity 2018;6:634-43.

6. Fang A, Hu SS, Endres N, et al. Risk factors for infection after spinal surgery. Spine (Phila Pa 1976) 2005;30:1460-5.

7. Nahhas CR, Hu K, Mehta AI. Incidence and risk factors of wound complications in long segment instrumented thoracolumbar spinal fusions: a retrospective study. J Spine Surg 2018;4:233-40.

8. Janjua MB, Toll B, Ghandi S, et al. Risk Factors for Wound Infections after Deformity Correction Surgery in Neuromuscular Scoliosis. Pediatr Neurosurg 2019;54:108-15.

9. Newton PO, Bastrom TP, Yaszay B. Patient-Specific Risk Adjustment Improves Comparison of Infection Rates Following Posterior Fusion for Adolescent Idiopathic Scoliosis. J Bone Joint Surg Am 2017;99:1846-50.

10. Sullivan BT, Abousamra O, Puvanesarajah V, et al. Deep Infections After Pediatric Spinal Arthrodesis: Differences Exist with Idiopathic, Neuromuscular, or Genetic and Syndromic Cause of Deformity. J Bone J Surg Am 2019. [Epub ahead of print].

11. Weinstein MA, McCabe JP, Cammisa FP. Postoperative spinal wound infection: a review of 2,391 consecutive index procedures. J Spinal Disord 2000;13:422-6.

12. Pull ter Gunne AF, Cohen DB. Incidence, prevalence, and analysis of risk factors for surgical site infection following adult spinal surgery. Spine (Phila $\mathrm{Pa}$ 1976) 2009;34:1422-8.

13. Floccari LV, Milbrandt TA. Surgical site infections after pediatric spine surgery. Orthop Clin North Am 2016;47:387-94.

14. Park HY, Sheppard W, Smith R. The combined administration of vancomycin $\mathrm{IV}$, standard prophylactic antibiotics, and vancomycin powder in spinal instrumentation surgery: does the routine use affect infection rates and bacterial resistance? J Spine Surg 2018;4:173-9.

15. Shaffer WO, Baisden JL, Fernand R, et al. An evidencebased clinical guideline for antibiotic prophylaxis in spine surgery. Spine J 2013;13:1387-92.

16. Klekamp J, Spengler DM, McNamara MJ, et al. Risk factors associated with methicillin-resistant staphylococcal wound infection after spinal surgery. J Spinal Disord 1999;12:187-91.

17. Bakhsheshian J, Dahdaleh NS, Lam SK. The use of vancomycin powder in modern spine surgery: systematic review and meta-analysis of the clinical evidence. World Neurosurg 2015;83:816-23.

18. Khan NR, Thompson CJ, DeCuypere M, et al. A metaanalysis of spinal surgical site infection and vancomycin powder. J Neurosurg Spine 2014;21:974-83.

19. Chiang HY, Herwaldt LA, Blevins AE, et al. Effectiveness of local vancomycin powder to decrease surgical site infections: a meta-analysis. Spine J 2014;14:397-407.

20. O'Neill KR, Smith JG, Abtahi AM, et al. Reduced surgical site infections in patients undergoing posterior spinal stabilization of traumatic injuries using vancomycin powder. Spine J 2011;11:641-6.

21. Sweet FA, Roh M, Sliva C. Intrawound application of vancomycin for prophylaxis in instrumented thoracolumbar fusions: efficacy, drug levels, and patient outcomes. Spine (Phila Pa 1976) 2011;36:2084-8.

22. Strom RG, Pacione D, Kalhorn SP, et al. Decreased risk of wound infection after posterior cervical fusion with routine local application of vancomycin powder. Spine (Phila $\mathrm{Pa}$ 1976) 2013;38:991-4.

23. Martin JR, Adogwa O, Brown CR, et al. Experience with intrawound vancomycin powder for spinal deformity surgery. Spine (Phila Pa 1976) 2014;39:177-84.

24. Ghobrial GM, Cadotte DW, Williams K Jr, et al. Complications from the use of intrawound vancomycin in lumbar spinal surgery: a systematic review. Neurosurg Focus 2015;39:E11.

25. Rathbone CR, Cross JD, Brown KV, et al. Effect of various concentrations of antibiotics on osteogenic cell viability and activity. J Neurosurg Spine 2016;25:147-53.

26. Singh K, Samartzis D, Heller JG, et al. The management of complex soft-tissue defects after spinal instrumentation. J Bone Joint Surg Br 2006;88:8-15.

27. Mehbod AA, Ogilvie JW, Pinto MR, et al. Postoperative deep wound infections in adults after spinal fusion: Management with vacuum-assisted wound closure. J Spinal 
Disord Tech 2005;18:14-7.

28. Canavese F, Gupta S, Krajbich JI, et al. Vacuum- assisted closure for deep infection after spinal instrumentation for scoliosis. J Bone Joint Surg Br 2008;90:377-81.

29. Lee R, Beder D, Street J, et al. The use of vacuum-assisted closure in spinal wound infections with or without exposed dura. Eur Spine J 2018;27:2536-42.

30. Watt JP, Dunn RN. The use of vacuum dressings for death space management deep surgical site infections allows implant and bone graft retention. Global Spine J 2017;7:756-61.

Cite this article as: Daldal I, Senkoylu A. Strategies of management of deep spinal infection: from irrigation and debridement to vacuum-assisted closure treatment. Ann Transl Med 2020;8(2):33. doi: 10.21037/atm.2019.11.60
31. Richards BS. Delayed infections following posterior spinal instrumentation for the treatment of idiopathic scoliosis. J Bone Joint Surg Am 1995;77:524-9.

32. Hedequist $\mathrm{D}$, Haugen A, Hresko $T$ et al. Failure of attempted implant retention in spinal deformity delayed surgical site infections. Spine 2009;34:60-4.

33. Farshad M, Sdzuy C, Min K. Late implant removal after correction of AIS with pedicle screw instrumentation. A matched case control study with 10 -year follow-up. Spine Deform 2013;1:68-71. 